\title{
Novel, High Brightness X-ray Source and High Efficiency X-ray Optic for Development of X-ray Instrumentation
}

\author{
Wenbing Yun ${ }^{1}$, SH Lau ${ }^{1}$, Benjamin Stripe ${ }^{1}$, Alan Lyon ${ }^{1}$, David Reynolds ${ }^{1}$, Sylvia JY Lewis ${ }^{1}$, Sharon \\ Chen $^{1}$, Vladimir Semenov ${ }^{1}$ and Richard Ian Spink ${ }^{1}$ \\ 1. Sigray, Inc. Concord, CA USA
}

In the past two decades, laboratory $\mathrm{x}$-ray analysis equipment has made significant strides, particularly toward higher resolution capabilities [1-2]. The major bottleneck to continued advances to achieving simultaneously achieving higher sensitivity, resolution, and throughput is the relatively low flux of x-rays at the sample for micro-characterization techniques such as SAXS, high resolution XRD, microXRF, and $\mathrm{x}$-ray microscopy [3]. We present two major innovations of a microfocus X-ray source and a high resolution, high efficiency $\mathrm{x}$-ray optic to enable delivery of flux comparable to second generation bending magnet synchrotrons.

The proprietary Sigray FAAST ${ }^{\mathrm{TM}}$ source features an anode comprised of arrays of metal (e.g. $\mathrm{Cu}, \mathrm{W}$ ) microstructures x-ray emitters embedded in a diamond substrate, which enables highly localized and large thermal gradients to passively and rapidly cool the metal microstructures as X-rays and heat are generated under the bombardment of electrons. Electron power densities of over $4 \mathrm{X}$ can be achieved on the target in comparison to conventional solid metal targets for the case of copper - and even greater for metals of lower thermal conductivity. The thermal advantages of the x-ray source will critically enable the use of many elements that were previously considered infeasible as $\mathrm{x}$-ray source materials, and therefore will enable access to new x-ray characteristic lines to optimize performance in monochromatic X-ray analysis. The source enables linear accumulation of x-rays along a set of microstructures, which further increases the substantial brightness gain.

We will also discuss advances made to Sigray's proprietary axially symmetric x-ray mirror lens designs, particularly in regards to the key performance attributes that must be evaluated when considering an x-ray optic for microanalytical applications, including: focusing efficiency, numerical aperture (NA), FWHM of point spread function, working distance, focus chromaticity, energy bandpass, energy transmission, percent of source brightness preservation, and phase space acceptance.

Several of the key breakthroughs that Sigray has made in regards to the development of the mirror lens include optimizing the preservation of the ultrahigh brightness of small spot sized x-ray sources (e.g. the Sigray FAAST ${ }^{\mathrm{TM}}$ source, transmission nanofocus sources, and liquid metal jet anode x-ray sources). Additionally, the lens enables unprecedented capabilities for focusing low energy x-rays to microns-scale spot sizes, which can potentially unlock many applications for laboratory analysis, such as microXRF of low atomic number elements and increased sensitivity of grazing incidence and surface analysis. The imaging nature and achromatic nature of the lens moreover provide a single focal spot for x-rays of all energies, which has conventionally been a limitation to the accuracy of microanalytical techniques that rely on polycapillary lenses (which produce differing illumination spot sizes on the sample and thus results in the emission of interfering X-rays from outside of the intended focal spot). [4] 


\section{References:}

[1] T Skarzynski. Acta Crystallographica Section D (2013)

[2] Tsuji et al. Spectrochemica Acta Part B: Atomic Spectroscopy (2015)

[3] MT Cole et al. Nanotechnology 27 (2016)

[4] The authors acknowledge funding from the NSF, Division of Industrial Innovation \& Partnerships for the development of x-ray mirror lens (IIP-1448727) and the NIH, National Institute of General Medicine Science for the development of the microstructured source target (GRANT11545218).

Table 1.

\begin{tabular}{|c|c|c|c|}
\hline $\begin{array}{l}\text { Performance } \\
\text { Attributes }\end{array}$ & Polycapillary & Sigray Ellipsoid & $\begin{array}{l}\text { Sigray Double } \\
\text { Paraboloid }\end{array}$ \\
\hline Imaging optic & Not an imaging optic (condensing optic) & Fair & Excellent \\
\hline $\begin{array}{l}\text { Transmission } \\
\text { efficiency }\end{array}$ & $\sim 5-10 \%$ & $\sim 90 \%$ & $\sim 80 \%$ \\
\hline $\begin{array}{l}\text { Numerical aperture } \\
@ 8 \mathrm{keV}^{\#}\end{array}$ & $<50 \mathrm{mrad}$ & 10 mrad by Sigray & 20mrad by Sigray \\
\hline $\begin{array}{l}\text { FWHM of point } \\
\text { spread function } \$\end{array}$ & $\begin{array}{l}\text { Minimum size equal to capillary diameter, } \\
\text { inversely proportional to x-ray energy, } \\
\text { proportionally increase with working } \\
\text { distance }\end{array}$ & $\begin{array}{l}\text { Independent on } x-\text { ray } \\
\text { energy, determined by } \\
\text { figure error } \\
(<10 \mu \mathrm{m} \text { by Sigray })\end{array}$ & $\begin{array}{l}\text { Independent on } x-\text { ray } \\
\text { energy, determined by } \\
\text { figure error. } \\
\text { (<10 } \mu \mathrm{m} \text { by Sigray) }\end{array}$ \\
\hline $\begin{array}{l}\text { Working distance for } \\
10 \mu \mathrm{m} \text { focus }\end{array}$ & $\begin{array}{l}1,0.5 \text {, and } 0.25 \mathrm{~mm} \text { for } 17,8 \text {, and } 4 \mathrm{keV} \mathrm{x}^{-} \\
\text {rays, respectively }\end{array}$ & $\begin{array}{l}1-10 \mathrm{~cm} \text { depending on } \\
\text { figure error }(>2 \mathrm{~cm} \text { by } \\
\text { Sigray) }\end{array}$ & $\begin{array}{l}\text { 1-10 cm depending on } \\
\text { figure error ( }>2 \mathrm{~cm} \text { by } \\
\text { Sigray) }\end{array}$ \\
\hline Focus chromaticity & $\begin{array}{l}\text { Focus size inversely proportional to x-ray } \\
\text { energy }\end{array}$ & achromatic & achromatic \\
\hline Spectral bandpass & $\begin{array}{l}\text { Wide with a high energy cut-off which is } \\
\text { dependent on specific optic }\end{array}$ & $\begin{array}{l}\text { Wide with a high energy } \\
\text { cut-off }\end{array}$ & $\begin{array}{l}\text { Wide with a high energy } \\
\text { cut-off }\end{array}$ \\
\hline $\begin{array}{l}\text { Spectral } \\
\text { transmission }\end{array}$ & $\mathrm{OK}$ & Good & Good \\
\hline $\begin{array}{l}\text { Percent of source } \\
\text { brightness } \\
\text { preservation }\end{array}$ & $\begin{array}{l}\text { Substantial reduction with a source of size } \\
\text { smaller than the FWHM of point spread } \\
\text { function }\end{array}$ & Fair & Excellent \\
\hline $\begin{array}{l}\text { Normalized Phase } \\
\text { space acceptance }\end{array}$ & 1 & 3 & 3 \\
\hline
\end{tabular}

